\title{
Erratum to: Movement of Heparins Across Rat Gastric Mucosa is Dependent on Molecular Weight and pH
}

\author{
Bita Moazed $^{1}$ and Linda M. Hiebert ${ }^{1,2}$
}

Erratum to: Pharmaceutical Research

DOI 10.1007/s11095-008-9751-8

This article was published with an incorrect unit. Throughout the article, mA should be $\mu \mathrm{A}$ (the Greek letter "mu" replacing the English letter "m"). This includes units in the Figures 1 and 2 and Table I.

\footnotetext{
${ }^{1}$ Department of Veterinary Biomedical Sciences, Western College of Veterinary Medicine, University of Saskatchewan, 52 Campus Drive, Saskatoon, Saskatchewan S7N 5B4, Canada.

${ }^{2}$ To whom correspondence should be addressed. (e-mail: linda.hiebert@usask.ca)
}

The online version of the original article can be found at http://dx.doi.org/10.1007/s11095-008-9751-8. 